UDC: 821.134.2.09-1 Cernuda L. 821.134.1.09-1 Bartra A. DOI: https://doi.org/10.18485/beoiber.2017.1.6

\author{
Blanca Ripoll Sintes ${ }^{1}$ \\ Universitat de Barcelona \\ España
}

\title{
EL DESARRAIGO EN LUIS CERNUDA Y AGUSTÍ BARTRA: UNA VISIÓN COMPARADA DESDE LOS ESTUDIOS IBÉRICOS
}

\section{Resumen}

Este artículo trata de establecer relaciones entre dos grandes poetas del siglo XX: el andaluz Luis Cernuda y el catalán Agustí Bartra, desde la óptica de los Estudios lbéricos. Los parámetros comunes se trazarán a partir del concepto de desarraigo y de la metafísica del exilio de María Zambrano. En este sentido, se analizarán sus obras y sus biografías.

Palabras clave: Luis Cernuda, Agustí Bartra, Exilio, María Zambrano, Estudios Ibéricos.

\section{THE UPROOTING OF LUIS CERNUDA AND AGUSTÍ BARTRA: A COMPARATIVE VISION FROM THE IBERIAN STUDIES VIEWPOINT}

\begin{abstract}
This article aims to establish relations between two great poets in the $20^{\text {th }}$ century: the Andalusian Luis Cernuda and the Catalan Agustí Bartra, from the point of view of Iberian Studies. The common parameters will be defined through the concept of uprooting and through María Zambrano's metaphysics of exile. In this manner, we will analyze their works and biographies.

Key words: Luis Cernuda, Agustí Bartra, Exile, María Zambrano, Iberian Studies.
\end{abstract}

\section{La diversidad cultural y lingüística del Exilio Republicano Español. Una mirada desde los Estudios lbéricos}

Santiago Pérez Isasi observa la consolidación académica, universitaria, de los Estudios lbéricos como un fenómeno reciente, gestado en los últimos quince años, frente

\footnotetext{
1 blancaripoll@ub.edu
} 
a las cuatro décadas de investigaciones puntuales que buscaban acercar, comparar, sistematizar, los fenómenos culturales que la realidad plural de la Península Ibérica ofrecía en su análisis diacrónico. En este sentido, asevera el investigador del Centro de Estudios Comparatistas que:

(...) el estudio de Iberia como espacio geocultural unitario se integra en la recuperación de los Area Studies, desde una perspectiva distinta a la que dominó estas disciplinas durante la Guerra Fría (...), pero también debe relacionarse con el giro espacial de las humanidades, y en concreto con el cuestionamiento de la historia literaria, tanto en su formulación historicista-narrativa como en su limitación lingüística o nacionalista (Pérez Isasi 2014: 20).

Esta nueva perspectiva metodológica nos permitirá abordar el estudio de un concepto fundamental para el exilio republicano: el desarraigo, en dos poetas fundamentales en sus respectivos campos culturales -la terminología es de Bourdieu (1995)-, Luis Cernuda y Agustí Bartra, sin relación aparente. Podría pecar de atrevimiento al abordar dos biografías sin contacto conocido, pero en ocasiones es de gran interés analizar cómo determinadas circunstancias históricas generan respuestas culturales similares, sin necesidad de que existan relaciones intertextuales o personales reales.

Ahondando un poco más, debemos partir de la condición de poetas y de exiliados que Cernuda y Bartra comparten. Dicha condición nos llevará a viajar irremediablemente hasta México, país de acogida de ambos escritores después de sendos periplos vitales por Europa y Estados Unidos. El país centroamericano destacó muy pronto por ser uno de los pocos estados que demostraron una enorme solidaridad hacia el gobierno de la II República y hacia muchos intelectuales de nuestro país, ofreciéndoles no solo la entrada libre sino también, en muchos casos, un trabajo que permitiera su subsistencia.

Agustí Bartra, escritor catalán autodidacta, vivió la retirada del ejército republicano en 1939 en primera persona y sufrió la condena posterior, como otros miles republicanos, de ir malviviendo en diversos campos de concentración franceses (Argelers, Saint Ciprien, Agde). Afortunadamente, en el mes de agosto del 39, Francesc Trabal lo rescata de las durísimas condiciones de la vida de los campos y lo ayuda a refugiarse en un castillo cercano a París (en Roissy-en-Brie), donde se va a reencontrar con otros escritores catalanes y donde dará comienzo a una relación amorosa con quien sería su compañera vital, la también escritora Anna Murià. Ante la invasión alemana de Francia, la pareja inicia su periplo americano: visitan en 1940 la República Dominicana; en 1941, Cuba; y, ese mismo año, México, donde se establecen definitivamente hasta 1970 (con breves estancias en los Estados Unidos), fecha en que regresaron a Cataluña.

A su vez, Cernuda acabó también sus días en México después de una larga travesía por diversos exilios anglosajones. El poeta andaluz salió de España en 1938, después de haber acompañado al gobierno republicano hasta Valencia, en dirección a Inglaterra, invitado por un amigo de la embajada para que ofreciera una serie de conferencias a favor de la causa republicana. Se inicia así un período (1938-1947) en el que Cernuda 
mantiene todavía la esperanza de regresar a España: sufre duras circunstancias económicas y sus carencias en el dominio del inglés le dificultan en grado sumo su integración en los países de acogida. En 1947, con la certidumbre de que el régimen de Franco es ya un sistema estable, da el salto a Estados Unidos para trabajar en el Mount Holyoke College (Massachusetts), donde vivirá hasta 1952. Desde 1949 realiza diferentes estancias en México y Cuba, espacios donde trabará relaciones con otros españoles exiliados y con parte de la intelectualidad mexicana. Estas vivencias lo seducirán profundamente y lo conducirán a establecerse en México de forma definitiva en 1952. Alternará el país de Centroamérica con cortas visitas al sur de Estados Unidos, como hizo Bartra y por el mismo motivo que el poeta catalán: mejorar sus respectivas situaciones económicas, gracias a pensiones $\mathrm{y}$ pagos por conferencias $\mathrm{y}$ ediciones procedentes de instituciones norteamericanas (universidades, fundaciones, etc.). Cernuda morirá en México en 1963.

\section{El sujeto "transterrado". La experiencia del idioma en Cernuda y Bartra}

La experiencia reveladora que México supuso para Cernuda tiene mucho que ver con el concepto que acuñó el filósofo José Gaos, también exiliado en México, de "transterrados", frente al más común de "exiliados"; noción que, de alguna forma, modificaba los parámetros de análisis y sustituía el binomio patria-territorio, por el de patria-idioma. Si la patria, el hogar colectivo, era el idioma, los individuos simplemente habían sido transterrados, transportados a un territorio que compartía su idioma y, por tanto, la patria, y, por tanto, el hogar. Así lo explicaba el filósofo, formado en Valencia, en "Confesiones de un transterrado": "(...) queriendo expresar cómo no me sentía en México desterrado sino..., se me vino a las mientes y a la voz la palabra transterrado, que sin duda quedó ajustada a la idea que había querido expresar con sinceridad" (Gaos 1992: 546).

Precisamente de esta forma lo vive Luis Cernuda. El poeta se reencuentra en México con antiguos amigos, como Moreno Villa, Manuel Altolaguirre, Emilio Prados; queda seducido por la realidad mexicana, por su forma de entender el tiempo, la vida y el placer (en una carta a Raúl Leiva, confiesa: “El dinero no lo es todo; aquí en México gano menos dinero que en los EEUU; sin embargo, me siento tranquilo, feliz. Aquello me era insoportable..." - Cernuda 1975: 798). En definitiva, Cernuda seguirá siendo en México un exiliado político, pero abandona su condición de "desterrado", cuestión que reencontraremos más adelante. En una carta a José Luis Cano, su editor en la España interior durante el Franquismo, le explica su relación con María Zambrano y con José Lezama Lima en Cuba, y cuán cerca de su patria le hace sentir hallarse en un país que comparte su idioma: 
Algunos me preguntan si no echo de menos mi tierra, después de una ausencia de más de doce o trece años. Esa gente no comprende todavía algo que yo comprendo ya: que España, México, Cuba y probablemente cualquier país de lengua española forman una unidad, y no me siento extraño, ni pierdo mi cariño a España, por vivir en otra tierra de mi lengua (Amat 2002: 217).

Por su parte, podríamos aventurar que Agustí Bartra podía sentirse transterrado "a medias", partiendo del hecho de que México le ofrecía un territorio con una lengua que dominaba como el español y una vasta red de republicanos españoles y catalanes que pudo acoger a la pareja Bartra-Murià; si bien el idioma esencial -y en consecuencia, la patria y el hogar- de Bartra era el catalán. México fue, también en este sentido, un país generoso y protegió y facilitó el desarrollo de numerosas iniciativas de la intelectualidad catalana en el exilio. Buena muestra de ello fueron revistas como El Poble Català de Mèxic, Full Català, fundada por Josep Carner, Lletres o la mítica Pont Blau; la celebración de los Jocs Florals de la Llengua Catalana (durante los cuales Agustí Bartra fue galardonado con el premio Fastenrath en su convocatoria de 1942 con la novela Xabola, primera redacción del Crist dels 200.000 braços); o la edición de obras en catalán (hecho que también aprovechó Bartra).

Por otro lado, no cabe dibujar dos comunidades estancas, lingüísticamente separadas, en territorio mexicano. Todo lo contrario, la colaboración fue frecuente y se demuestra a partir de la biografía bartriana. Baste como botón de muestra la edición y el prólogo que realizó del libro Presencia de García Lorca (1943).

Asimismo, el poeta catalán rechazará siempre -aunque en una obra más militante políticamente que la cernudiana- el panfleto que implica la carencia estética, literaria, artística (como se ejemplifica en la polémica sostenida entre Bartra y Carner, y el grupo que acabó gestionando los Quaderns de l'exili, dirigidos por Joan Sales y Lluís Ferran); y se manifestará contrario también a la reivindicación lingüística e identitaria de una patria reduccionista. Explica con vehemencia en una carta a Pere Calders:

O s'escriu en l'idioma de la gran llibertat de la creació o no s'escriu en cap. No s'és humà en català, castellà, francès, etc.: se n'és no en virtut d'un instrument, sinó per gràcia d'un valor i d'una qualitat essencial d'home envers els altres homes. Em sento tan català que sempre m'ha inspirat repugnància el nacionalisme de "saltataulells" dels patriotes oficials. He begut les aigües pures de la pàtria profunda. No m'he triat el meu destí, però l'he assumit, i per tal de no ésser destruït he hagut d'adoptar estratègies de supervivència² (Murià 2004: 231).

2 Damos nuestra traducción del catalán original: “O se escribe en el idioma de la gran libertad de la creación o no se escribe en ninguno. No se es humano en catalán, castellano, francés, etc.: se es humano no en virtud de un instrumento, sino por la gracia de un valor y de una cualidad esencial de hombre frente a otros hombres. Me siento tan catalán que siempre me ha inspirado repugnancia el nacionalismo de "principiantes" de los patriotas oficiales. He bebido las aguas puras de la patria profunda. No he escogido mi destino, pero lo he asumido y para no ser destruido he tenido que adoptar estrategias de supervivencia". 
Estrategias que lo llevarán a autotraducirse sus obras al español, como medio económico, pero también como plataforma para relacionarse con la intelectualidad mexicana; esta cuestión provocó que cuando Bartra publicó Quetzalcòatl en una primera versión en español, diversos miembros del grupo de Quaderns boicotearon su difusión. La patria de Bartra va más allá de fronteras e idiomas: tiene un sustrato mítico y nace en el crisol del Mediterráneo: "L'esperit no parla en cap idioma, parla en tots -diu ell-. Tinc un mall, però dues encluses. El que importa és la qualitat de la forja”³ (Murià 2004: 269).

\section{El desarraigo: María Zambrano, Luis Cernuda y Agustí Bartra}

Es interesante detenerse en la noción de destierro, vinculada al desarraigo del exiliado, fase que, como hemos visto, experimenta Cernuda durante su etapa anglosajona y que teoriza, con su lucidez habitual, María Zambrano en su filosofía auroral del exilio (como también era "auroral" el hombre nuevo que tenía que llegar según Bartra, imagen presente en numerosos poemas). Zambrano reivindicará siempre la existencia y las injusticias cometidas durante el Franquismo, pero también en democracia, contra los exiliados del país: Carta sobre el exilio, de 1961, o Amo mi exilio, de 1989, son buena prueba de su deseo de convertirse en una figura incómoda para los discursos oficiales, que buscaba evidenciar la tragedia y ejercer como testimonio para las generaciones futuras.

No obstante, será capaz de trascender su circunstancia individual para erigir el exilio en eje fundamental de su pensamiento, para convertirlo en problema filosófico y como punto de partida necesario para provocar que la filosofía sea, para el individuo, una forma de vida, un saber de la experiencia. En obras como Delirio y destino (1952), La tumba de Antígona (1967) o Los bienaventurados (1990) nos ofrece una reflexión constante sobre el sentido del exilio y del destierro, convirtiendo ambas nociones en piedras angulares de una auténtica metafísica humana.

Asevera Zambrano en La tumba de Antígona: "Eso es el destierro, una cuesta, aunque sea en el desierto. Esa cuesta que sube siempre y, por ancho que sea el espacio a la vista, es siempre estrecho" (Zambrano 1993: 92). En dicha obra, la filósofa describe al desterrado como aquel que está sumido en un sueño, que "ha quedado atónito, sin llanto y sin palabra, como en estado de pasmo" (Zambrano 1993: 37). La metafísica del exilio zambraniana clasifica en tres etapas, al modo de las tres vías de la mística española aurisecular, las diferentes experiencias que el individuo puede acometer durante su exilio: la experiencia del refugiado, la del desterrado y la del exilio logrado. Determinadas personas pueden instalarse en una fase concreta y no salir de ella nunca más. No obstante, Zambrano insta a que lleguemos a la etapa final, la del exilio logrado. El exiliado se perfila, en el pensamiento de Zambrano, como un superviviente, alguien

3 “El espíritu no habla en ningún idioma, habla en todos ellos -dice él-. Tengo un mazo, pero dos yunques. Lo que importa es la calidad de la fragua". 
destinado a morir, pero que fue rechazado por la misma muerte; como alguien a quien dejaron en vida, pero:

(...) tan solo y hundido en sí mismo y a la par, a la intemperie, como uno que está naciendo; naciendo y muriendo al mismo tiempo, mientras sigue la vida. La vida que le dejaron sin que él tuviera culpa de ello; toda la vida y el mundo, pero sin lugar en él, habiendo de vivir pero sin poder acabar de estar (Zambrano 1961: 66).

Así, el dolor del destierro no es nunca un pozo sin fondo, un callejón sin salida para Zambrano, sino el principio y el motor de la lucha incesante y apasionada que debe ser la vida. En consecuencia, el exilio se transforma en la obra de la pensadora malagueña en un reto vital que el individuo debe merecer alcanzar. Un exilio que, en palabras de Zambrano, "ha sido como mi patria, o como una dimensión de una patria desconocida, pero que una vez que se conoce, es irrenunciable" (ibidem).

Esta vivencia irrenunciable del exilio es plenamente compartida por Agustí Bartra y Luis Cernuda. En el caso del escritor catalán, podemos establecer un paralelismo entre la concepción de Zambrano sobre el exilio y la de Bartra acerca del exilio, pero también de la Guerra Civil y de la experiencia en los campos concentracionarios. Todas ellas son vivencias dolorosas que conducen al individuo a una experiencia radical, apasionada $y$ urgente de cada momento, $\mathrm{y}$, a la vez, se convierten en motores de conocimiento y de creación artística. Así, Bartra confesaría que la Guerra:

-Em centrà definitivament com a poeta pel que tenia de projecció dramàtica absoluta, i em madurà com a home en sentir-me profundament home i profundament humà entre altres homes que se m'assemblaven. Avorreixo la guerra, però mai no podré oblidar el que li dec 4 (Murià 2004: 45).

Podemos añadir además que, desde un primer momento, aunque se hallaba en las terribles condiciones de los campos franceses (experiencia exorcizada en Xabola), Bartra asume su condición de exiliado como único destino posible y rechaza las peticiones de su padre para que vuelva, así como las posibilidades ofrecidas por Francia a los prisioneros para regresar en tren hacia España.

En esta misma línea, en un recital en el Centre Català de l'Havana, el 13 de marzo de 1941, Bartra señalaba a la Guerra y al exilio como auténticos motores de una nueva poesía y de una nueva metafísica de la identidad catalana:

Ens mancava una irreductible mística de pàtria, que ara existeix dispersa entre els supervivents de la tragèdia. Aquesta és la gran experiència de la guerra, i en

4 «-Me centró definitivamente como poeta por lo que tenía de proyección dramática absoluta, y me maduró como hombre al sentirme profundamente hombre y profundamente humano entre otros hombres que se me parecían. Repudio la guerra, pero nunca podré olvidar lo que le debo".

BEOIBERÍSTICA Vol. I / Número 1 (2017) | 93-102 
sorgirà la gran esperança. La Catalunya de flabiol i de ginesta ha entrat discretament a la història5 (Murià 2004: 131-132).

Un último apunte que compartirán Cernuda y Bartra radica en el proceso de vivencia y asimilación del exilio, a través de la catarsis que para ellos supone la creación literaria. Las etapas experienciales del exiliado se pueden observar en la obra de ambos; etapas que en grandes líneas se pueden resumir en una ecuación reduccionista como la de: destierro y dolor, idealización del pasado, y militancia perenne de su condición de exiliado.

En el caso del poeta andaluz, la Guerra Civil, sus circunstancias, los amigos perdidos y el exilio condicionan la escritura de Las nubes, donde hallamos dos poemas que resumen dos momentos fundamentales de la vida del exiliado: la nostalgia y el desarraigo del desterrado. Los dos textos se titulan "Impresión de destierro" y "Un español habla de su tierran. En el primero, el poeta se desdobla y se observa a sí mismo, alienado, en la figura de un hombre de acento extranjero, "un acento de niño en voz envejecida", un hombre sin rostro, fatigado y silencioso, "con la misma fatiga / del muerto que volviera / desde la tumba a una fiesta mundana" (Cernuda 1993: 294), que le revela al final del poema que la España que ha vivido Cernuda ha muerto.

En el segundo texto de Las nubes, Cernuda cae en la lógica tentación de idealizar el pasado que se echa en falta: "Las playas, parameras / al rubio sol durmiendo, / los oteros, las vegas / en paz, a solas, lejos; / (...)" (Cernuda 1993: 310). Pasado y país que le han arrebatado: «ellos, los vencedores / Caínes sempiternos, / de todo me arrancaron. / Me dejan el destierro" (ibid.). Y mientras, toma cuerpo la amargura de la espera del escritor, que se nutre de los recuerdos de aquello hurtado, y aparece el cruel y verdadero vaticinio: “Un día, tú ya libre / de la mentira de ellos, / me buscarás. Entonces / ¿qué ha de decir un muerto?" (ibid.)

La sensación de desarraigo se mezcla con un gran rencor en la mayoría de poemas que Cernuda dedica a Inglaterra. Así se observa en "La partida", incluida en Vivir sin estar viviendo - 1944-1949, donde revela: “Nada suyo guardaba aquella tierra / donde existiera. Por el aire, / como error, diez años de la vida / vio en un punto borrarse. / (...) (Adiós al fin, tierra con tu gente fría, / donde un error me trajo y otro error me lleva. / Gracias por todo y por nada. No volveré a pisarte)" (Cernuda 1993: 423).

La frialdad física, climatológica, emocional y moral del país británico y de su gente son los auténticos parámetros que presiden el desarraigo de Cernuda. El poeta echa de menos, más que el país o la patria, el clima moral y físico de su Andalucía natal, que aparecerá en los poemas como el paraíso perdido. Así, el reencuentro con la calidez de Málaga en el país de México supondrá un cambio radical en la experiencia cernudiana del

\footnotetext{
5 "Carecíamos de una irreductible mística de la patria, que ahora existe dispersa entre los supervivientes de la tragedia. Esta es la gran experiencia de la guerra, y de ella nacerá una gran esperanza. La Cataluña del flautín y la ginesta ha entrado discretamente en la historia".
} 
exilio y se observa en la alegría y la sensualidad de los poemas en prosa de Variaciones sobre un tema mexicano (1952): "En un abrazo sentiste tu ser fundirse con aquella tierra; a través de un terso cuerpo oscuro, oscuro como la penumbra, terso como fruto, alcanzaste la unión con aquella tierra que lo había creado. Y podrás olvidarlo todo, todo menos ese contacto de la mano sobre un cuerpo, memoria donde parece latir, secreto y profundo, el pulso mismo de la vida" (Cernuda 1990: 60-61). El sol, un amor nuevo y la tierra se reconcilian en esta nueva fase del exilio cernudiano.

A pesar de eso, el poeta asume su condición de exiliado de forma permanente. Así ocurre en el estremecedor poema "Peregrino" de Desolación de la Quimera (1962):

¿Volver? Vuelva el que tenga,

tras largos años, tras un largo viaje,

cansancio del camino y la codicia

de su tierra, su casa, sus amigos,

del amor que al regreso fiel le espere.

Mas, ¿tú? ¿Volver? Regresar no piensas,

sino seguir libre adelante

(...)

Sigue, sigue adelante y no regreses,

fiel hasta el fin del camino y tu vida,

no eches de menos un destino más fácil (Cernuda 1993: 530).

Como reza también uno de sus últimos textos, “1936", canto épico en homenaje agradecido a los brigadistas internacionales:

Recuérdalo tú y recuérdalo a otros, cuando asqueados de la bajeza humana,

cuando iracundos de la dureza humana;

este hombre solo, este acto solo, esta fe sola.

Recuérdalo tú y recuérdalo a otros.

(...)

Por eso otra vez hoy la causa te aparece

como en aquellos días:

noble y tan digna de luchar por ella (Cernuda 1993: 544).

En Bartra, la experiencia de la Guerra Civil nutre numerosos textos, desde los poemas de L'arbre de foc (1946), pasando por sus relatos breves, hasta la representación literaria que hizo de su vida en los campos en Xabola (1942) o Crist dels 200.000 braços (1968). Con todo, y manifestándose contrarios a la barbarie de las armas, los textos bartianos muestran siempre una profunda fe en la capacidad transformadora del hombre, una esperanza de un futuro mejor (no ideal, sino que nace de la acción concreta), una fe en "l'Home vestit d'hora vermella!", es decir, el hombre auroral (Bartra 1985: 106). 
Esta visión esperanzadora es, con frecuencia, la gran diferencia respecto de la vivencia que Cernuda describe del exilio en sus poemas. Si Cernuda nos habla de peregrinaje perpetuo, Bartra evoca en "Els Poemes d'Odisseu" (segunda parte de L'evangeli del vent - 1956) el mito de Ulises, tamizado por su mirada particular: Odiseo no se queja ante el largo camino que tiene por delante, sino que asume su destino de apátrida y se enfrenta al viaje con deseo de conocimiento y de vida: "Perdut i retrobat, vaig fent del meu exili / un gran himne d'adéus"6 (Bartra 1985: 126); o "Dels teus retorns faig les meves naixences. / Vinc del no-res i marxo cap al tot” ${ }^{7}$ (Bartra 1985b: 127). Del mismo modo, la vida en el campo francés será también motivo de crecimiento personal, como explica el poema "Argelers": "A la sorra va néixer el meu cant de vidència. / Vora l'antiga mar, entre adormits, / s'alçà / el guerrer de l'espiga, l'atlant verd de mon ànima. (...) $)^{8}$ (Bartra 1985b: 140).

Bien es cierto que también el recuerdo de Cataluña y las quejas hacia la tierra de acogida, que nunca podrá sustituir a la tierra de origen, entran en los textos de Bartra. El poema "Estances d'Atzingo", también de L'evangeli del vent, exclama: "Oh terra sense autumnes, de ràpides entranyes, / de déus feixucs i ingràvids colibrís: / no em lliga allò que serves, i, mirant tes muntanyes, / més certes sento les del meu país. (...)"9 (Bartra 1985b: 181). Años antes, a su paso por la República Dominicana y Cuba, había escrito "Oda a Catalunya des dels Tròpics" (escrita en 1944 e incluida en L'arbre de foc de 1946), en la que rechaza la nostalgia, pues la concibe como un sentimiento yermo y victimista, y reclama la vivencia continua de la patria, porque "icom podria enyorar-te si no t'has desprès de mi, / si ets tan forta d'existència com l'amor en el refugi dels cossos?."10 (Bartra 1985a: 73-74).

No obstante, el agradecimiento a México y la asunción emocional e intelectual de su realidad y de su cultura penetrarán en la obra bartriana con ejemplos como Quetzalcòatl (1960/ 1971) y La lluna mor amb aigua (1968).

\section{Breve nota a modo de conclusión}

Quizá como clausura de esta inusual comparativa, podríamos establecer que nuestros dos escritores fueron dos outsiders de sus propias tradiciones -durante su vida-,

6 "Perdido y encontrado, hice de mi exilio / un gran himno de despedidas".

7 "De tus regresos construyo mis nacimientos / Vengo de la nada y camino hacia el todo".

8 "En la arena nació mi canto visionario. / Al lado de la mar antigua, entre dormidos, / se levantó / el guerrero de la espiga, el atlante verde de mi alma".

9 "Oh tierra sin otoños, de rápidas entrañas, / de dioses pesados e ingrávidos colibrís: / no me ata lo que cobijas, $y$, mirando tus montañas, / más ciertas siento las de mi país".

10 "¿cómo podría añorarte si no te has desprendido de mí, / si eres tan poderosa de existencia como el amor en el refugio de los cuerpos?». 
si bien serían reivindicados y saludados como maestros a su muerte. Poetas de la modernidad, asumieron la tradición precedente, pero serían los jóvenes escritores y poetas quienes los erigirán en modelos de escritura lírica (lo demuestran el homenaje que el grupo de la revista Cántico dedicó a Cernuda o numerosos fragmentos que lo atestiguan de la Crònica de la vida d'Agustí Bartra de Anna Murià). Dos escritores que asumieron su condición trágica de exiliados, no como bandera política, sino como destino vital, espiritual y poético.

\section{BIBLIOGRAFÍA}

Amat, Jordi. Luis Cernuda. Fuerza de soledad. Madrid: Espasa, 2002. Impreso.

Bartra, Agustí. Crist dels 200.000 braços. Barcelona: Proa, 1982. Imprès.

-. L'arbre de foc. Obres Completes. Barcelona: Edicions 62, 1985a. Imprès.

-. L'evangeli del vent. Obres Completes. Barcelona: Edicions 62, 1985b. Imprès.

-. Presencia de García Lorca. México: Darro, 1943. Impreso.

Bourdieu, Pierre. Las reglas del arte: génesis y estructura del campo literario. Barcelona: Anagrama, 1995. Impreso.

Cernuda, Luis. Prosas completas. Barcelona: Barral Editores, 1975. Impreso.

-. Variaciones sobre tema mexicano. México: Consejo Nacional para la Cultura y las Artes, 1990. Impreso.

-. Poesía Completa. Vol. I. Madrid: Siruela, 1993. Impreso.

Gaos, José. "Confesiones de Transterrado", Obras Completas. México: UNAM, t. VIII, 1992. Impreso.

Murià, Anna. Crònica de la vida d'Agustí Bartra. Barcelona: Publicacions de l'Abadia de Montserrat, 2004. Imprès.

Pérez Isasi, Santiago, "Relaciones culturales Ibéricas. Presentación". 1616: Anuario de Literatura Comparada, 4, 2014, 19-24. Impreso.

Zambrano, María. "Carta sobre el exilio". Cuadernos del Congreso por la libertad de la cultura, 49, 1961. Impreso.

-. Los bienaventurados. Madrid: Siruela, 1991. Impreso.

-. La tumba de Antígona. Madrid: Mondadori, 1993. Impreso.

-. "Amo mi exilio". Gómez Blesa, M. (ed.), Las palabras del regreso, Salamanca: Amaru, 1995. Impreso.

-. Delirio y destino. Madrid: Horas y Horas, 2011. Impreso.

Fecha de recepción: 11 de enero de 2017. Fecha de aceptación: 11 de marzo de 2017. 